\title{
EUS-guided coil placement for acute gastric variceal bleeding induced by non-EUS-guided variceal glue injection (with video) $\square$
}

\section{(ㄷ)(1) $(-)$}

\author{
Authors \\ Institutions \\ 1 Section of Gastroenterology, Department of Medicine, \\ Haukeland University Hospital, Bergen, Norway, \\ 2 Department of Clinical Medicine 1, University of Bergen, \\ Bergen, Norway. \\ 3 Department of Radiology, Haukeland University \\ Hospital, Bergen, Norway,
}

Tarek Mazzawi ${ }^{1,2}$, Carl Erik Markhus ${ }^{3}$, Roald F. Havre ${ }^{1,2}$, Khanh Do-Cong Pham ${ }^{1,2}$

submitted 9.7.2018

accepted after revision 22.10 .2018

\author{
Bibliography \\ DOI https://doi.org/10.1055/a-0826-4253 | \\ Endoscopy International Open 2019; 07: E380-E383 \\ (c) Georg Thieme Verlag KG Stuttgart · New York \\ ISSN 2364-3722
}

Corresponding author

Tarek Mazzawi, MD, PhD, Section of Gastroenterology, Department of Medicine, Haukeland University Hospital, Jonas Lies vei 65, 5020 Bergen, Norway

Fax: +4755974785

tarek.mazzawi@gmail.com

\section{ABSTRACT}

Background and study aims Endoscopic ultrasound (EUS)-guided coil placement is a new emerging technique for management of gastric varices. In this video case report, we describe an EUS-guided coil placement for managing acute bleeding of gastric varices, following an unsuccessful glue injection to achieve hemostasis.

\section{Introduction}

Gastric varices (GV) are found in $20 \%$ of patients with portal hypertension, and account for $2 \%$ to $5 \%$ of all variceal bleeding [1-2]. Acute hemorrhage from GVs occurs less frequently but is more severe than esophageal varices (EVs) [1]. According to current practice guidelines, endoscopic band ligation and glue injection are the recommended conventional endoscopy-guided treatment modalities for EVs and GVs, respectively [3]. However, several complications are associated with glue injection, most importantly, increased risk of glue emboli and pulmonary embolism [4]. In case of uncontrolled or re-bleeding following glue injection therapy of GVs, the next therapeutic option is placement of transjugular intrahepatic portosystemic shunt (TIPS) to reduce portal hypertension and indirectly halt the bleeding [5].

Endoscopic ultrasound (EUS)-guided coil placement is a new emerging technique for management of GV bleeding. We describe EUS-guided single coil placement to treat acute GV bleeding following glue injection that was unsuccessful to achieve hemostasis.

\section{Case report}

A 51-year-old male with known primary sclerosing cholangitis and liver cirrhosis was referred to the endoscopy lab to receive n-butyl-2-cyanoacrylate (Histoacryl blue, B. Braun, United States) injection therapy of GV. The patient had no history of bleeding from the varices, but elimination of the GVs was a prerequisite from the transplantation center (Rikshospitalet, Oslo University Hospital, Oslo, Norway) before undergoing liver transplantation. Presence of GVs was confirmed by endoscopy and computed tomography (CT) images. Results of the patient's blood tests before and after the procedure are shown in - Table 1. Under sedation with intravenous (IV) midazolam and alfentanil, upper endoscopy was performed using a therapeutic gastroscope (2TH-180, Olympus, Tokyo, Japan). EVs were seen at the distal part of the esophagus and protruding GVs ( $\triangleright$ Fig. 1), seen by retroflection of the endoscope, were located at the fundus (Sarin GOV2 [2]). An injection needle (injection needle SU, 6-mm, 21-gauge, Endo-Flex GmbH, Voerde, Germany) was used to puncture the varix. Following injection of a 1.3-mL mixture of $0.8 \mathrm{~mL}$ of ethiodized poppyseed oil (Lipiodol, Guerbet, France) and $0.5 \mathrm{~mL}$ of n-butyl-2-cyanoacrylate flushed with sterile water, acute bleeding occurred when the needle was retracted, rapidly filling the stomach with blood and ob- 
Table 1 Blood tests levels before, the day of and 4 days after the endoscopic procedure.

\begin{tabular}{|c|c|c|c|}
\hline Blood test & Before endoscopy & Day of endoscopy & 4 days post-endoscopy \\
\hline Hemoglobin (g/dl) & 14.2 & 8.4 & 9.6 \\
\hline $\mathrm{MCV}(\mathrm{fL})$ & 90 & 90 & 90 \\
\hline Leucocytes $\left(10^{*} 9 / \mathrm{L}\right)$ & 3.8 & 3.9 & 6.2 \\
\hline Thrombocytes $\left(10^{*} 9 / \mathrm{L}\right)$ & 56 & 55 & 63 \\
\hline Ammonium (umol/L) & 55 & - & 27 \\
\hline $\operatorname{CRP}(\mathrm{mg} / \mathrm{l})$ & 5 & 8 & 18 \\
\hline Creatinine (umol/L) & 58 & 53 & 55 \\
\hline $\mathrm{Na}(\mathrm{mmol} / \mathrm{L})$ & 138 & 138 & 131 \\
\hline $\mathrm{K}(\mathrm{mmol} / \mathrm{L})$ & 4.0 & 4.0 & 3.2 \\
\hline $\operatorname{ALT}(U / I)$ & 169 & 89 & 90 \\
\hline AST (U/I) & 201 & 107 & 110 \\
\hline $\operatorname{ALP}(U / I)$ & 327 & 168 & 201 \\
\hline GT (U/I) & 327 & 156 & 178 \\
\hline Bilirubin (umol/L) & 33 & 26 & 25 \\
\hline Albumin (g/L) & 33 & - & 27 \\
\hline INR & 1.3 & 1.3 & 1.4 \\
\hline
\end{tabular}

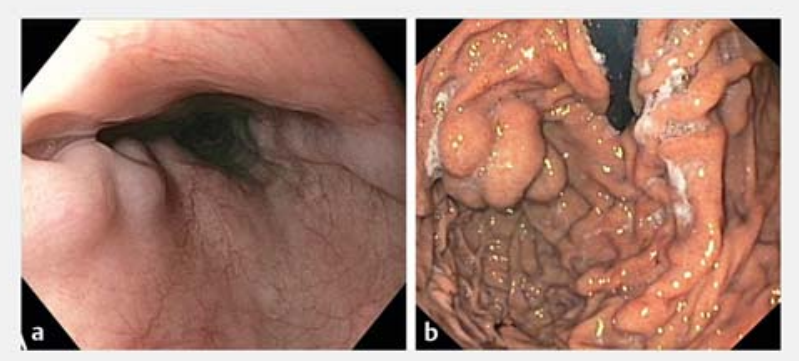

- Fig. 1 Endoscopic pictures of a esophageal and $\mathbf{b}$ gastric fundus varices.

scuring the endoscopic view, rendering further gluing attempts impossible.

The patient rapidly became circulatory unstable with signs of shock and was immediately intubated. Thereafter, the procedure was continued under general anesthesia. Due to the unavailability of urgent TIPS, an endoscopic ultrasound was performed ( $\triangleright$ Video 1 ) using linear array echoendoscope (Pentax EG-3870TK, Tokyo, Japan) and large GVs $(30 \times 20 \mathrm{~mm})$ were identified as round and oval-shaped anechoic structures within the submucosa ( $>$ Fig. 2a), and were confirmed by demonstration of flow using color-Doppler ( $\triangleright$ Fig. $2 b$ ). The previously injected n-butyl-2-cyanoacrylate glue mass was identified as a hyperechoic structure that was not completely filling the lumen of the GVs ( $\triangleright$ Fig.2c). Under EUS guidance, a 19-gauge EUS

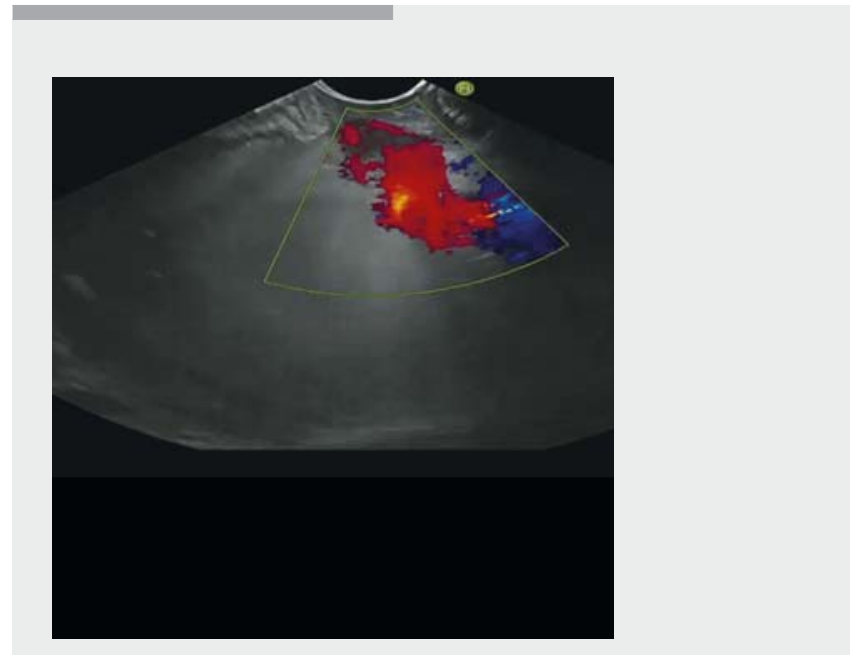

Video 1 EUS-guided coil placement in an acutely bleeding gastric varix.

needle (EchoTip, Cook Medical, Salem, Massachusetts, United States) was used to puncture the vessel of the GV. Based on the size of the vessels, a single 12-mm coil for intravascular use (Nester, Cook Medical, Bloomington, Indiana, United States) was placed inside the varix, through the EUS needle ( $\triangleright$ Fig. 2d). After placement, the Doppler signal in the vessels ceased. Further injections with n-butyl-2-cyanoacrylate were not required following coil placement. 

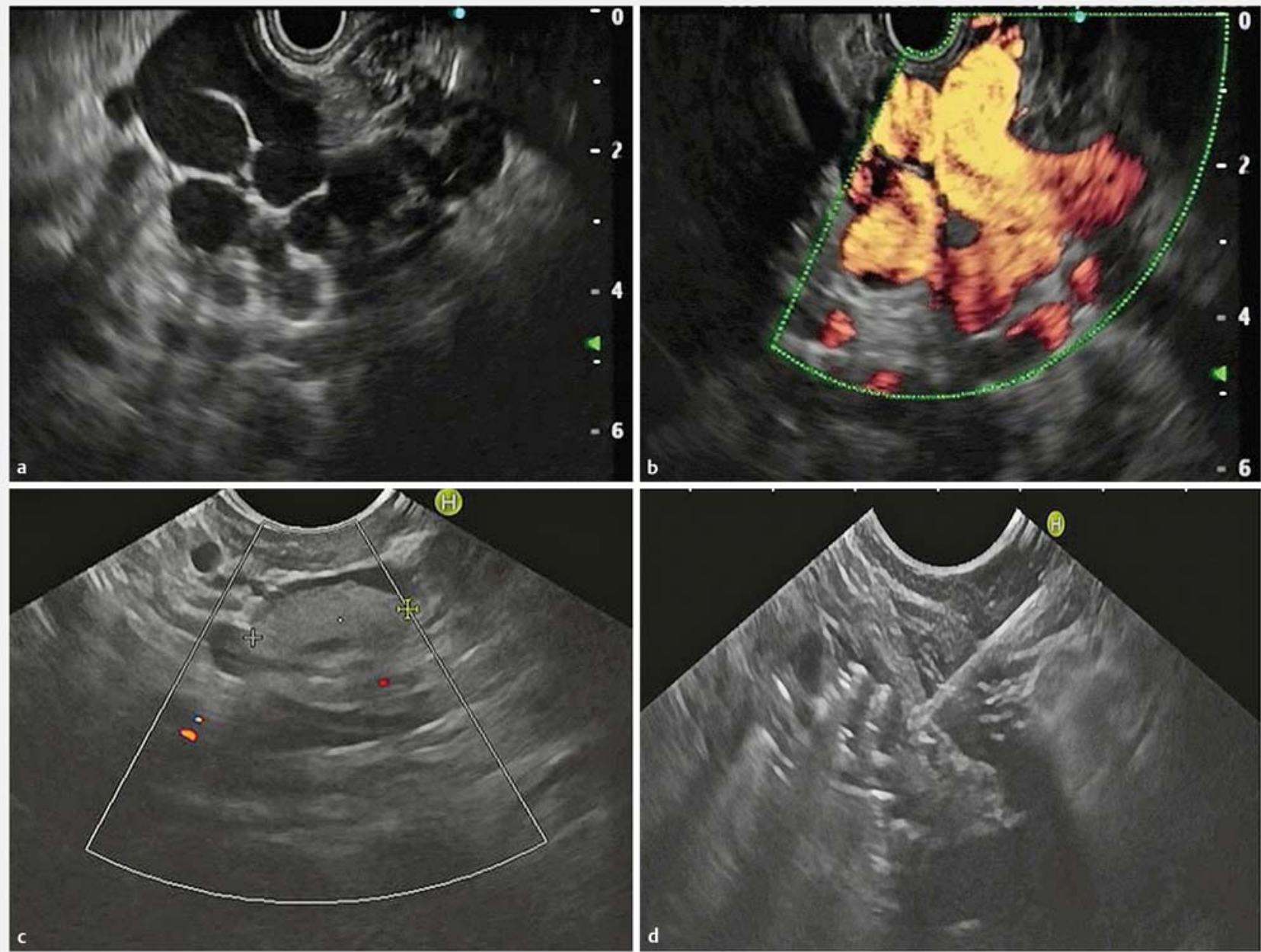

- Fig. 2 Endosonographic pictures of the large gastric varices. a Identified as round and oval-shaped anechoic structures without color-Doppler. b Demonstration of flow by color-Doppler. $\mathbf{c}$ Glue in the varix lumen. $\mathbf{d}$ Coil deployed by EUS needle into the varix lumen.

During the procedure, the patient received 1 unit of packed red blood cells, 2 units of fresh frozen plasma and 2 units of thrombocytes, in addition to terlipressin $2 \mathrm{mg}$ IV. The patient was then observed in the intensive care unit and continued to receive terlipressin $1 \mathrm{mg} \times 6 \mathrm{IV}$, broad-spectrum antibiotics (cefotaxim $2 \mathrm{~g} \times 3$ IV and erythromycin $250 \mathrm{mg} \times 2$ IV to enhance gastric emptying) and proton pump inhibitor (pantoprazole $40 \mathrm{mg} \times 3 \mathrm{IV}$ ). A second-look endoscopy was performed after 4 days and showed continued hemostasis ( $>$ Fig. $\mathbf{3}$ ). The patient was readmitted after 3 weeks for another medical reason and a CT scan was taken and showed the previously placed coils in the GVs ( $\triangleright$ Fig.4). No further variceal bleeding had been reported.

\section{Discussion}

EUS -guided coil placement has been used for treatment of esophagogastric and ectopic varices [6-7]. Coils that are currently used for intravascular embolization treatments can be delivered via fine-needle puncture into a varix under EUS guidance and, when used in conjunction with n-butyl-2-cyanoa-

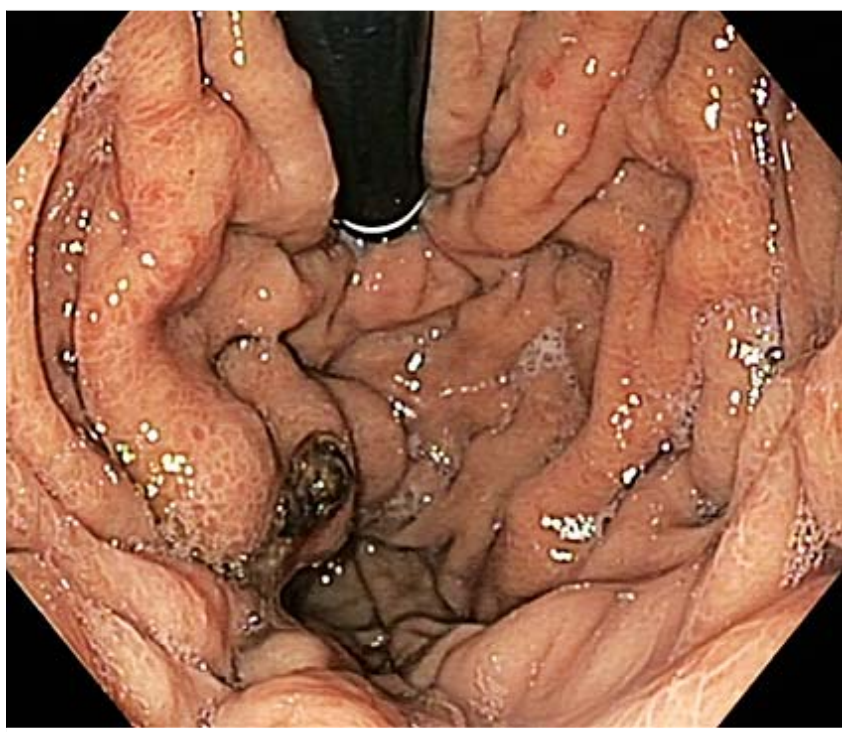

Fig. 3 A second-look endoscopy after 4 days confirming continued hemostasis. 


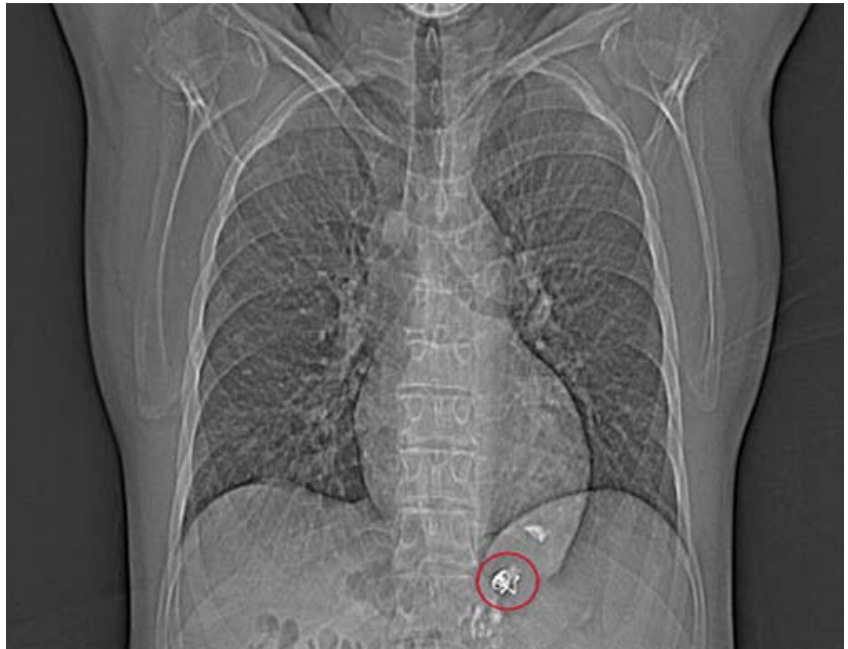

- Fig. 4 Antero-posterior CT thorax picture showing the placed coils (encircled) in the gastric varices 3 weeks post-treatment.

crylate injection, may reduce risk of glue embolization. The synthetic fibers ("wool coils") covering the coils promote thrombosis and function as a scaffold to retain n-butyl-2-cyanoacrylate (Histoacryl blue) within the varix and may decrease the amount of glue injection needed to achieve obliteration [8].

Previous publications suggest that EUS-guided coil placement can also be used to treatment different varices [6] but has been largely reserved as rescue therapy for refractory bleeding [9]. EUS-guided coil placement can also be used along with glue injection to stop bleeding gastric varices and is also suggested as primary prophylaxis [7], in the absence of use of prophylactic sclerotherapy [2], due to its theoretic advantages over conventional endoscopy-guided treatment [9]. This approach was found to be both feasible and safe [8-10].

In our case, EUS-guided coil placement was effective and possibly life-saving in the absence of alternative treatment options. Although glue injection was technically successful, the amount of injected glue did not fill the lumen of the large-sized varices, as was seen using EUS and this also may have increased risk of embolism if more glue was injected. EUS-guided coil placement can be implemented as salvage therapy when initial hemostasis (i. e. glue injection) is unsuccessful, leading to acute GV bleeding or when early post-treatment bleeding occurs.

\section{Competing interests}

None

\section{References}

[1] Sarin SK, Lahoti D, Saxena SP et al. Prevalence, classification and natural history of gastric varices: a long-term follow-up study in 568 portal hypertension patients. Hepatology (Baltimore, Md) 1992; 16: $1343-1349$

[2] Sarin SK, Kumar A. Gastric varices: profile, classification, and management. Am J Gastroenterol 1989; 84: 1244-1249

[3] Garcia-Tsao G, Sanyal A], Grace ND et al. Prevention and management of gastroesophageal varices and variceal hemorrhage in cirrhosis. Hepatology (Baltimore, Md) 2007; 46: 922 - 938

[4] Hwang SS, Kim HH, Park SH et al. N-butyl-2-cyanoacrylate pulmonary embolism after endoscopic injection sclerotherapy for gastric variceal bleeding. J Comput Assist Tomogr 2001; 25: 16 - 22

[5] Loffroy R, Estivalet L, Cherblanc V et al. Transjugular intrahepatic portosystemic shunt for the management of acute variceal hemorrhage. World J Gastroenterol 2013; 19: 6131-6143

[6] Fujii-Lau LL, Law R, Wong Kee Song LM et al. Endoscopic ultrasound (EUS)-guided coil injection therapy of esophagogastric and ectopic varices. Surg Endosc 2016; 30: 1396-1404

[7] Bhat YM, Weilert F, Fredrick RT et al. EUS-guided treatment of gastric fundal varices with combined injection of coils and cyanoacrylate glue: a large U.S. experience over 6 years (with video). Gastrointest Endosc 2016; 83: $1164-1172$

[8] Rose SC. Mechanical devices for arterial occlusion and therapeutic vascular occlusion utilizing steel coil technique: clinical applications. AJF Am J Roentgenol 2009; 192: 321 - 324

[9] Weilert F, Binmoeller KF. EUS-guided vascular access and therapy. Gastrointest Endosc Clin North Am 2012; 22: 303 - 314

[10] Romero-Castro R, Ellrichmann M, Ortiz-Moyano C et al. EUS-guided coil versus cyanoacrylate therapy for the treatment of gastric varices: a multicenter study (with videos). Gastrointest Endosc 2013; 78: $711-721$ 